\title{
Dermoscopy of verrucous carcinoma of the nail bed
}

\section{Selma El Kadiri, Zakia Douhi, Mohammed Chaouche, Rhizlane Chaoui, Sara Elloudi, Hanane Baybay, Fatima Zahra Mernissi}

\author{
Department of Dermatology, CHU Hassan II, Fez, Morocco
}

Corresponding author: Dr. Selma El Kadiri, E-mail: elkadiri-s@hotmail.com

This was a 37-year-old farmer by profession, righthanded, with no notable pathological history who consulted 1 year ago for a nail lesion of the middle finger of the right hand initially treated as a wart without success. The evolution has been marked by the appearance of a budding tumor, papillomatous, warty, bleeding on contact destroying the nail and not overflowing on the periungual skin (Fig. la and 1b). Dermoscopy revealed peripheral papillomatous appearance, keratin deposits and hemorrhagic crusts (Fig. 2). The examination of the other nails was normal and the ganglionic areas were free. The rest of the somatic examination was peculiar. Cutaneous biopsy returned to favor verrucous hyperplasia. The X-ray of the middle finger had revealed a lysis of the last phalanx. After consulting the orthopedists, amputation of the phalangette was performed with simple postoperative follow-up. The histological study of the excision specimen showed hyperkeratosis with epidermal hyperplasia and pale keratinocytes limited to the basal layer confirming the diagnosis of verrucous carcinoma of the nail bed.

\section{Consent}

The examination of the patient was conducted according to the Declaration of Helsinki principles.

The authors certify that they have obtained all appropriate patient consent forms. In the form the patient(s) has/have given his/her/their consent for his/her/their images and other clinical information to be reported in the journal. The patients understand that their names and initials will not be published and due efforts will be made to conceal their identity, but anonymity cannot be guaranteed.

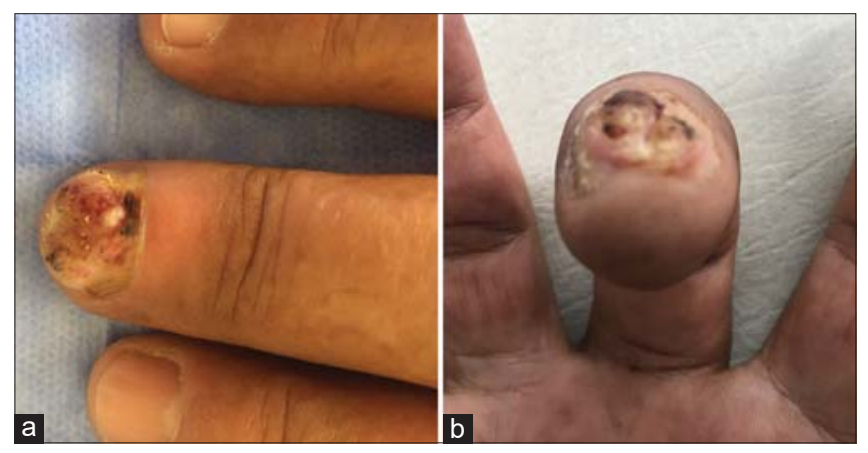

Figure 1: $(a$ and $b)$ Papillomatous, warty tumor of the middle finger of the right hand limited to the nail.

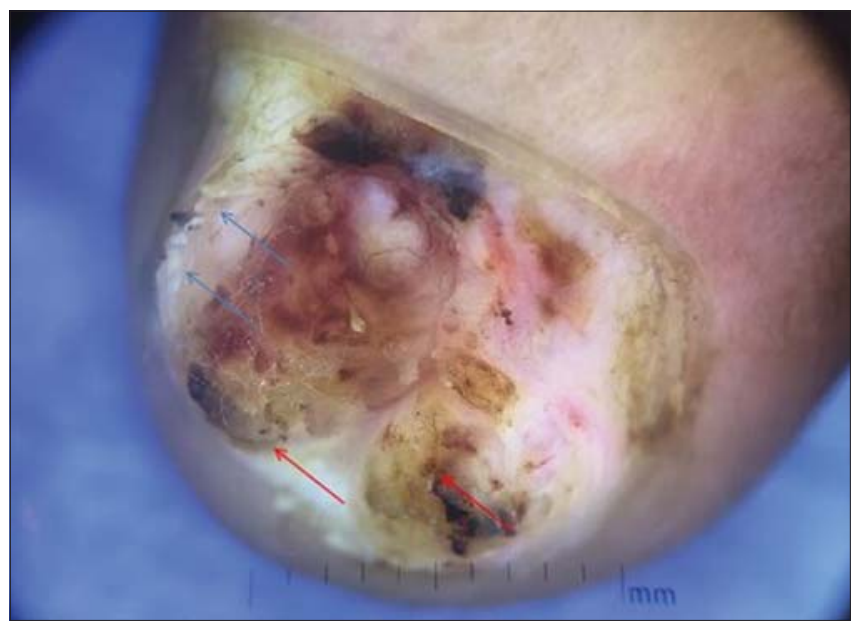

Figure 2: Dermoscopy of the nail tumor showing an aspect peripheral papillomatous (blue arrow) and yellowish deposits of keratin (red arrow).

Copyright by Selma El Kadiri, et al. This is an open-access article distributed under the terms of the Creative Commons Attribution License, which permits unrestricted use, distribution, and reproduction in any medium, provided the original author and source are credited. Source of Support: Nil, Conflict of Interest: None declared.

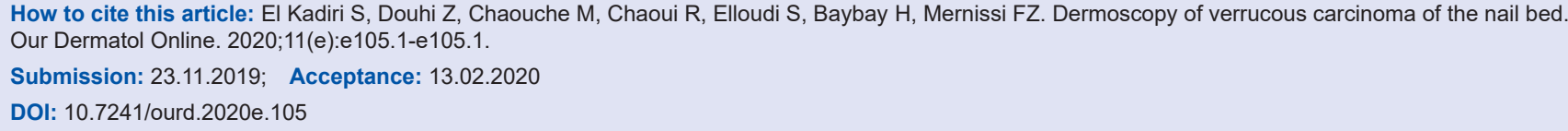

